\title{
A comparison of the efficacy of green house gas forcing and solar forcing
}

\author{
R.A. Irvine \\ SRG Industries, Queensland, Australia
}

\begin{abstract}
The efficacy (E) of a forcing is a measure of its capacity to generate a temperature response in the earth's system. Most Coupled Model Intercomparison Project Phase 5 (CMIP5) climate models assume that the efficacy of a solar forcing is close to the efficacy of a similar sized Green House Gas (GHG) forcing.

This paper examines the possibility that a change in short wave solar forcing may more readily contribute to ocean heat content $(\mathrm{OHC})$ than a similar change in long wave GHG forcing. If this hypothesis is shown to be correct, then it follows that equilibrium restoration times at the top of the atmosphere (TOA) are likely to be considerably faster, on average, for a change in GHG forcing than for a similar change in solar forcing.

A crude forcings model has been developed that matches almost perfectly $(\mathrm{R} 2=0.89)$ the National Oceanic and Atmospheric Administration (NOAA) temperature series from 1880 to 2010 . This model is compared to and performs much better over this period than the United Kingdom Met Office's (HadGEM2) contribution to the CMIP5 $\left(\mathrm{R}^{2}=0.16\right)$.

It is concluded, by implication that the efficacy of a GHG forcing is likely to be considerably lower than the efficacy of a similar sized solar forcing.
\end{abstract}

Keywords: Efficacy, Forcing, Greenhouse Gas, Solar, Sensitivity, Climate, Model,

\section{Introduction}

If for any reason the efficacy of a GHG forcing $\left(\mathrm{E}_{(\mathrm{GHG})}\right)$ can be shown to be significantly lower than $\mathrm{E}_{(\text {Solar })}$ then it should be possible to develop an Energy Balance Model (EBM) that explains the temperature history of the last century or 
more far more accurately than is currently possible. One possible reason for this difference in efficacy could be the large difference in water absorption between long wave GHG energy and short wave solar energy.

It is the current generally accepted belief that $\left(\mathrm{E}_{(\mathrm{GHG})}\right)$ in the earth's system is approximately equal to or slightly higher than $\mathrm{E}_{(\text {Solar) }}$. This belief is examined in this paper and is discussed in the Intergovernmental Panel on Climate Change (IPCC) Fifth Assessment Report (AR5) [1]. The IPCC's Fourth Assessment Report (4AR) [2], also, concludes that short wave solar forcing has a slightly lower $\left(\mathrm{E}_{(\mathrm{Solar})}=(0.7\right.$ to 1.0$\left.) \times \mathrm{E}_{(\mathrm{GHG})}\right)$ efficacy than long wave $\mathrm{GHG}$ forcing due to geographical and vertical distribution.

Forster [3], make the case that "Effective Climate Forcing" (ERF) is a much more useful way of estimating climate sensitivity than conventional; one size fits all, Radiative Forcing (RF). They make their case succinctly in the following quote;

"Imagine, for example, that the atmosphere alone (perhaps through some cloud change unrelated to any surface temperature response) quickly responds to a large Radiative Forcing to restore the flux imbalance at the TOA (Top Of Atmosphere), yielding a small effective climate forcing. In this case the ocean would never get a chance to respond to the initial Radiative Forcing, so the resulting climate response would be small and this would be consistent with our diagnosed "Effective Climate Forcing" rather than the conventional "Radiative Forcing."

It follows that a shorter response time at the TOA produces a lower climate sensitivity. Hansen [4] confirm and support this by saying "On a planet with no ocean or only a mixed layer ocean, the climate response time is proportional to climate sensitivity. Hansen et al (1985) show analytically, with ocean mixing approximated as a diffusive process, that the response time increases as the square of climate sensitivity."

If it can be shown that the restoration of the flux imbalance at the TOA is quicker, on average, for a perturbation in GHG forcing than it is for a similar perturbation in solar forcing, then this would imply a lower climate sensitivity for GHG forcing than solar forcing.

The earth has an ocean and it is established physics that Long wave Radiation from GHGs only penetrates the oceans to a depth of a fraction of a millimetre.

$99 \%$ of the long wave radiation reemitted by GHGs is absorbed in pure water in the first $0.015 \mathrm{~mm}$ of the surface. This can be calculated using the following equation;

$$
\mathrm{I}=\mathrm{I}_{0} \times \mathrm{e}^{-\mu \mathrm{L}}
$$

Where "I" is the Intensity at depth " $\mathrm{L}$ ", $\mathrm{I}_{0}$ is the original Intensity, and " $\mu$ " is the absorption coefficient in water for GHG energy centred on a wavelength of $15 \mu \mathrm{m}\left(\mu=10^{3.5} \mathrm{~cm}^{-1}\right)$.

The oceans are virtually opaque to these wave lengths. By comparison pure water is almost totally transparent to short wave solar radiation. Light absorption by pure water has been measured by an integrated cavity absorption meter. For 
energy of $418 \mathrm{~nm}\left(\mu=10^{-4.1} \mathrm{~cm}^{-1}\right)$, light drops to one thousandth of its original intensity after travelling about 1570 meters in pure water.

I propose that this large difference in absorption will have some effect on flux imbalance restoration times at the TOA. Despite this matter being pivotal to any understanding of the earth's climate response to increasing Anthropogenic GHGs (AGHG), I have been unable to find any literature supporting the generally held position that solar forcing and GHG forcing have approximately the same efficacy after the ocean/atmosphere interface has been considered.

It has been suggested that the top fraction of a millimetre of the ocean is heated by the long wave radiation (LWR) reemitted by GHGs and that this either acts as a blanket slowing the release of energy to the atmosphere or alternatively is comprehensively mixed by wave action and that these entirely different mechanisms warm the oceans almost exactly the same amount as solar energy which is transported radiatively to a depth of many meters..

Not only is it highly improbable that these entirely different mechanisms would have almost exactly the same effect on $\mathrm{OHC}$, it can, also, be shown by means of a simple experiment, "Appendix 1", that nearly all the Long Wave GHG energy is returned almost immediately to the atmosphere and space as latent heat of evaporation.

It is apparent that the situation described in Forster [3] is relevant to GHG forcing. In short, the" Effective Climate Forcing" of a GHG change is likely to be considerably less than the "Effective Climate Forcing" of a similar solar change.

Forster [5] find evidence of a possible as yet undisclosed negative long wave radiation feedback. This evidence would be neatly explained if the large difference in water absorption between GHG radiation and solar radiation resulted in shorter TOA forcing restoration times for a change in GHG forcing as is indicated in "Appendix 1".

As further support for this I propose a crude EBM that reproduces almost perfectly the NOAA temperature history from 1880 to $2010\left(\mathrm{R}^{2}=0.89\right)$. As far as I know the accuracy of this model is unprecedented and gives further support to the hypothesis that $\mathrm{E}_{(\mathrm{Solar})}$ is considerably higher than $\mathrm{E}_{(\mathrm{GHG})}$. The model is described below.

\section{Energy Balance Model (EBM)}

A crude EBM has been developed that performs significantly better than the HadGEM2 CMIP5 model at reproducing temperature. This is evident through visual inspection of the models, figure 1 verses figure 2 , and also through comparison of $\mathrm{R}^{2}$. The forcing model has an $\mathrm{R}^{2}$ of 0.89 suggesting a significantly better fit than the HadGEM2 CMIP5 model which has an $\mathrm{R}^{2}$ of 0.16 . The model (Figure 1) accurately reproduces the slope of the temperature rise from 1910 to 1940 , the cooling from 1940 to 1970, the slope of the temperature rise from 1970 to 1998 and the temperature hiatus of the last decade or more. 
It follows that as long as we have a physical basis for $\mathrm{E}_{(\mathrm{GHG})}$ being a lot lower than $\mathrm{E}_{(\text {Solar })}$ then the temperature history of the last decade, century and millennium can be accurately explained giving us increased confidence in future predictions. A possible physical basis for this is demonstrated in "Appendix 1".

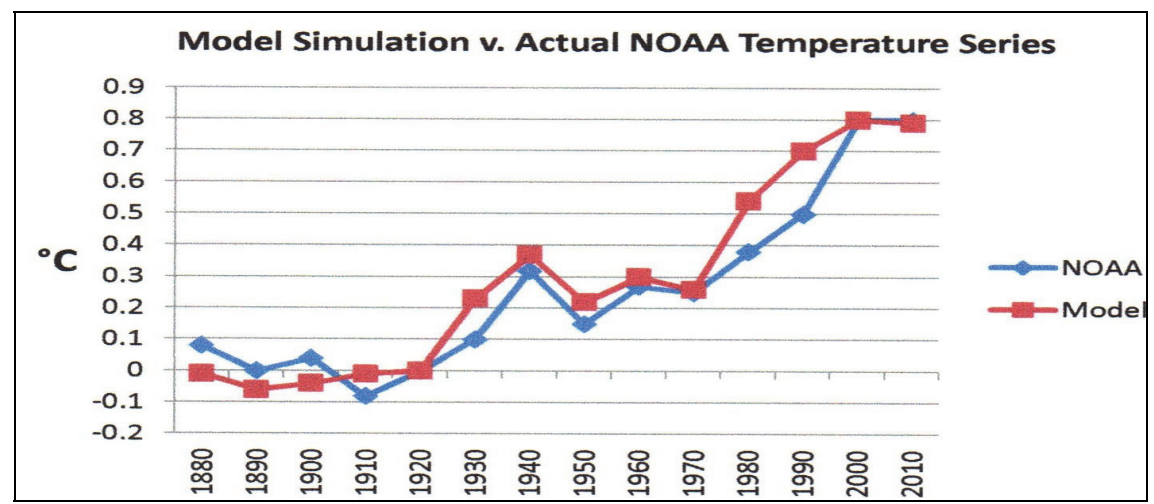

Figure 1: The Model supported by this paper (Red with large squares) compared to the NOAA actual temperature series (Blue with small diamonds). The cooling effect of volcanic activity is not included in this model and may explain some of the inconsistency in 1980 and 1990.

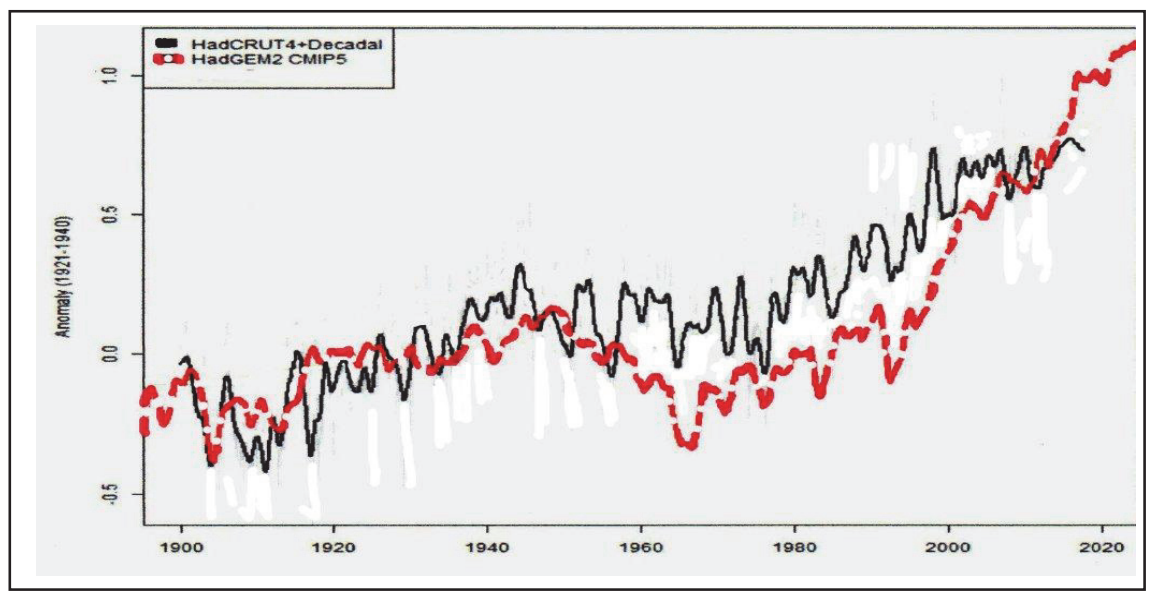

Figure 2: The HadGEM2 CMIP5 model (Red Broken Line) compared to the HadCRUT4 + Decadal measured temperature (Black Line). 
There are four immediate areas that need to be explained in the CMIP5 model in Figure 2 .

1. The temperature rise from 1910 to 1940 is too flat probably because the model's $\mathrm{E}_{\text {(Solar) }}$ is too low.

2. The cooling period from 1940 to 1970 is not replicated well and is too low probably because it's Aerosol cooling effect has been made too high to counter a too high $\mathrm{E}_{(\mathrm{GHG})}$.

3. The temperature hiatus since 1998 is not apparent probably because it's $\mathrm{E}_{(\mathrm{GHG})}$ is too high. The CMIP5 model shows a temperature increase of a little over $0.4^{\circ} \mathrm{C}$ for this period.

4. Any adjustment to internal variability, based on the Atlantic Multi-decadal Oscillation /Pacific Decadal Oscillation (AMO/PDO) index to account for the flat temperatures after 1998 will also make the 1940-1970 period less realistic.

The CMIP5 models in general are discussed in von Storch [6]. Their summary states;

"In contrast to earlier analysis for a ten year period that indicated consistency between models and observations at the 5\% confidence level, we find that the continued warming stagnation over 15 years, from 1998 to 2012, is no longer consistent with model projections even at the $2 \%$ confidence level. Of the possible causes of this inconsistency, the underestimation of internal natural climate variability on decadal time scales is a plausible candidate, but the influence of unaccounted for external forcing factors or an overestimation of the model sensitivity to elevated GHG concentrations cannot be ruled out."

\section{Discussion}

\subsection{Discussion A}

It is important to understand the concept of a tuning parameter or model plug. These tuning parameters are changed, often arbitrarily, in an attempt to make the model more closely fit the available data or other desired properties as described in Mauritsen [7] and quoted below.

"During a development stage global climate models have their properties adjusted or tuned in various ways to best match the known state of the Earth's climate system. These desired properties are observables, such as the radiation balance at the top of the atmosphere, the global mean temperature, sea ice, clouds and wind fields. The tuning is typically performed by adjusting uncertain, or even non-observable, parameters related to processes not explicitly represented at the model grid resolution. The practice of climate model tuning has seen an increasing level of attention because key model properties, such as climate sensitivity, have been shown to depend on frequently used tuning parameters."

Two examples of tuning parameters used by the CMIP5 models are aerosol forcing and ocean energy diffusion. Neither of these are well understood as can 
be seen by the wide range of values given to these two inputs in the models. That ocean energy diffusion is treated as a tuning parameter can be seen by the wide range in the ratio of transient climate response (TCR) to equilibrium climate response (ECR) of between 0.4 and 0.8 (average 0.57), Cohen-Tanugi [8], for the 18 models for which both values are provided in the $4 \mathrm{AR}$ report. Aerosols are also a tuning parameter as can be seen by the range in forcing used in an attempt to maximise the various models fit with measured temperatures and other desired properties. Below is a quote from the U.S. Government report, "Atmospheric Aerosol Properties and Climate Change" 2009, that clarifies this.

"This agreement across models appears to be a consequence of the use of very different aerosol forcing values, which compensates for the range of climate sensitivity. For example, the direct cooling effect of sulphate aerosol varied by a factor of six (6) among the models. An even greater disparity was seen in the model treatment of black carbon and organic carbon. Some models ignored aerosol indirect effects whereas others included large indirect effects. In addition, for those models that included the indirect effect, the aerosol effect on cloud brightness (reflectivity) varied by a factor of nine (9)."

One area that the CMIP5 models do not treat as a tuning parameter is the difference between $\mathrm{E}_{(\mathrm{Solar})}$ and $\mathrm{E}_{(\mathrm{GHG})}$. They, in fact, treat the approximate equivalence of these two factors as a desired property based on the vertical and geographical distribution of these two forcings in the atmosphere and tune their models to suit. They do not take account of the large difference in water absorption between long wave radiation and short wave radiation as can be seen from the following quotes from the $4 \mathrm{AR}$ and AR5.

Here is the relevant quote from the IPCC's 4AR, WG1, chapter 2.8.5; [2]

"Efficacy $(E)$ is defined as the ratio of the climate sensitivity parameter for a given forcing agent $\left(\lambda_{i}\right)$ to the climate sensitivity parameter for $\mathrm{CO}_{2}$ changes, that is, $E_{i}=\lambda_{i} / \lambda_{\mathrm{CO} 2} \ldots \ldots \ldots$.....

Many of the studies presented (4AR) find that both the geographical and vertical distribution of the forcing can have the most significant effect on efficacy ..... .

Nearly all studies that examine it find that high latitude forcings have higher E than tropical forcings. E has also been shown to vary with the vertical distribution of an applied forcing ..... .

Forcings that predominantly affect the upper atmosphere are often found to have smaller E compared to those that affect the surface ................ Overall there is medium confidence that the direct solar $E$ is within the 0.7 to 1.0 range."

The International Panel on Climate Change's (IPCC) Fifth Assessment Report (AR5) states clearly their belief that the Efficacy (E) of solar forcing (E solar) is approximately equal to $\left(\mathrm{E}_{\mathrm{GHG}}\right)$ in the following quotes from Working Group 1 (WG1) Chapter 8.1.1.3;[1]

"Using fixed-Sea Surface Temperature (SST) simulations Hansen et al (2005) found that Effective Radiative Forcing (ERF) is virtually identical to 
Radiative Forcing (RF) for increased $\mathrm{CO}_{2}$, tropospheric Ozone and solar irradiance..." and

"The various studies demonstrate that RF provides a good estimate of ERF in most cases, as the differences are very small, with the notable exception of Black Carbon (BC) related forcings."

The model supported by this paper (Fig 1) differs in that it treats the difference between $\mathrm{E}_{(\mathrm{Solar})}$ and $\mathrm{E}_{(\mathrm{GHG})}$ as a tuning parameter with the only desired property being that $\mathrm{E}_{(\mathrm{GHG})}$ be smaller than $\mathrm{E}_{(\mathrm{Solar})}$. It is of interest that this is the only Energy Balance Model (EBM) that can accurately model the measured temperature record from 1880 to 2010. All other EBMs fail unless they use extreme and atypical internal variability to explain the current temperature hiatus.

If we assume that internal variability explains most of the difference between the modelled and actual temperature from the HadGEM2 CMIP5 model in Fig 2, then this implied internal variability can be graphed and compared with the internal variability component for the model Fig 1 .

This has been approximated in Fig 3. It should be noted that the internal variability factor in Fig 1, shows regular peaks and troughs that are related to the AMO and PDO as would generally be expected. The implied internal variability from the HadGEM2 CMIP5 model in Fig 2, on the other hand, is atypical and is similar to the differenced internal variability for the CMIP 5 full set found in Mann [9]. Mann [9] gives an explanation for the atypical nature of this curve and is rebutted by Lewis [10]. In this context the term "atypical" refers to the almost total lack of any apparent internal variability in the first half of the $20^{\text {th }}$ century followed by large unexplained swings of 60 years or more to 2010 as seen in Figure 3.

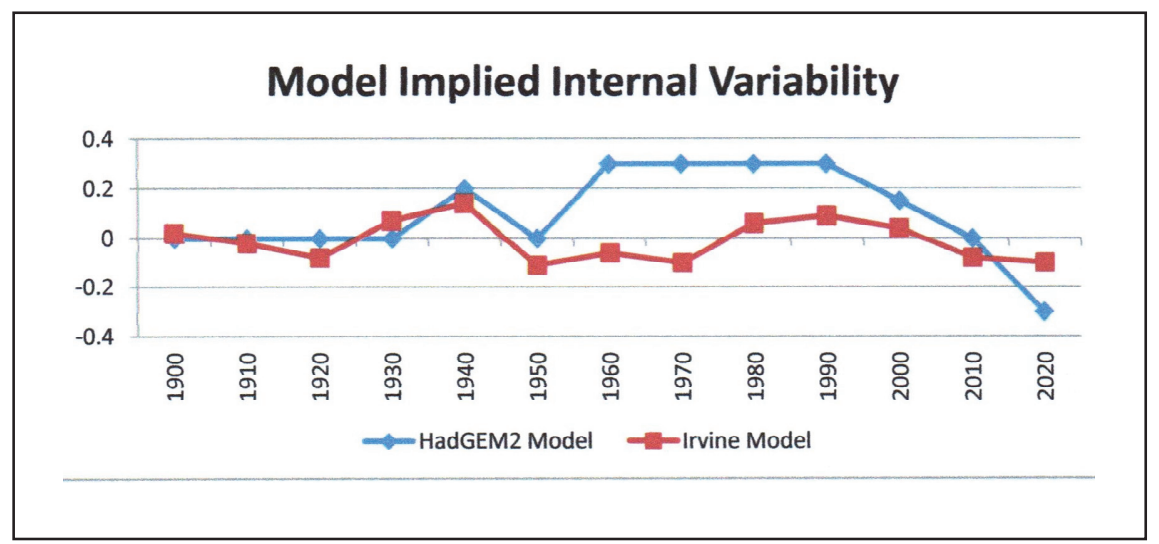

Figure 3: The blue line shows an approximation of the implied internal variability (degrees C) of the HadGEM2 CMIP5 model, figure 2, by differencing 
it with the HadCRUT4 temperature series, extrapolated to 2020. The red line is the internal variability used in the model Figure 1.

The CMIP5 models, effectively, need to use internal variability as a tuning parameter to help them match the measured temperature, particularly the atmospheric temperature hiatus of the last 15 to 18 years. This may be legitimate but appears to be inconsistent with the following two points and will need more study to define any limits.

1 The AR5 indicates that 10 to 15 year cooling or warming periods can be attributed to internal variability which is more consistent with the model Figure 1, than the HadGEM2 model. The relevant quote can be found in the WG1 AR5 Technical Summary TS 4.2 TS27 [11] and is copied below;

"Hiatus periods of 10-15 years can arise as a manifestation of internal decadal climate variability, which sometimes enhances and sometimes counteracts the long term external forcing trend.."

The Noaa climate report 2008, Peterson [12] also supports a 15 year limit for internal variability on page 23. Quote below.

"The simulations rule out (at the 95\% level) zero trends for intervals of $15 \mathrm{yr}$ or more, suggesting that an observed absence of warming of this duration is needed to create a discrepancy with the expected present-day warming rate."

2 The thermal expansion component of sea level rise has recently fallen to negligible levels as discussed in Cazenave [13] and documented in the National Oceanic and Atmospheric Administration (NOAA) paper "The budget of recent global sea level rise 2005-2012" revised in June 2012 by Eric Leuliette. This is not consistent with the increasing subsurface ocean heat uptake needed to balance the HadGEM2 model with measured temperatures in the last 10 years, but is consistent with long wave GHG radiation being almost totally absorbed within the evaporation layer of water.

\subsection{Discussion B}

Radiative transfer is significantly affected by oceanic pigment as discussed by Gordon [14] and Morel [15]. Ohlmann [16] showed that the heating rate of a 20 meter mixed layer can be changed by about $0.33^{\circ} \mathrm{C}$ per month by a solar radiative penetration that can reach $40 \mathrm{w} / \mathrm{m}^{2}$ in the tropical ocean. Siegel [17] concluded that a $10 \mathrm{w} / \mathrm{m}^{2}$ change in penetrative solar flux at 20 meters can result from a $0.10 \mathrm{mgm}^{-3}$ change in phytoplankton concentration.

These changes in radiative absorption have a significant effect on $\mathrm{OHC}$ and are approximated in the CMIP5 models for both GHG radiation and solar radiation. The energy from these two vastly different radiative sources is then diffused by various methods, but importantly, is treated the same for the purpose of this diffusion process.

What the CMIP5 models don't do is allow for the fact that the long wave GHG energy is almost entirely absorbed in the evaporation layer of water while solar energy is not. 
In general, if a photon of energy is absorbed by a water molecule it increases the velocity of that molecule. This increase in velocity may cause the molecule to break the surface tension of the water body or it may not. If the surface tension of the water is broken then evaporation occurs and both the introduced and original energy of the molecule is lost to the water body and that body is evaporatively cooled.

If, on the other hand, the molecule does not break the surface tension of the water body for any reason, including that it is too far from the surface, then the introduced energy remains in the water and warms that water.

If this is an accurate representation of what happens then it follows that down Long Wave Infrared Radiation (LWIR) could have a slight cooling effect in warmer water, and for colder water a slight warming effect.

The overall effect of this on the earth's OHC is difficult to quantify. What can be said is that LWIR from GHGs will have a different and smaller effect on OHC than a similar amount of solar radiation as the LWIR is nearly totally absorbed in the evaporation layer while nearly all short wave solar radiation is not.

\section{Model Inputs}

The input parameters for my model in Figure 1 are outlined below and were calculated on a best fit basis. They were limited to GHGs, solar, aerosols and an adjustment for internal variability based on a combination of the Atlantic Multidecadal Oscillation (AMO) and the Pacific Decadal Oscillation (PDO). These parameters can be changed on a best fit basis as other inputs are changed, added or improved and are outlined below.

\subsection{Solar}

There are two distinctly different types of solar forcing.

1. Changes in solar forcing that result from changes in Total Solar Irradiance (TSI) at the sun's surface, as usually measured by sunspot number, that are subject to any solar multiplier effects. Cosmic rays are the most commonly mentioned possible solar multiplier and are discussed in detail in Shaviv [18].

2. Changes in solar forcing that are caused by changes in albedo in the earth's system. Examples of this are volcanic activity and the Milankovich cycles that do not provoke any solar multiplier effect. These are discussed in Annan [19] and are the basis for many sensitivity studies.

The first type of solar forcing (Type 1 above) has a significant impact on the NOAA temperature series in Figure 1 and is, therefore, included in the model (Figure 1). The climate sensitivity to type 1 solar forcing at the earth's surface, as a best fit for the model (Figure 1), is $1.4^{\circ} \mathrm{C} / \mathrm{wm}^{-2}$. Hansen [4] found that between $60 \%$ and $90 \%$ of eventual equilibrium temperature is returned to the earth's atmosphere in the first 100 years. The range of ratio of transient climate response (TCR) to equilibrium climate response (ECR) is between 0.4 and 0.8 
(average 0.57 ) for the 18 models for which both values are provided in the 4AR [9] report. The input to the model (Figure 1) is, therefore, consistent with an equilibrium sensitivity of between, approximately, $1.6^{\circ} \mathrm{C} / \mathrm{wm}^{-2}$ and $3.5^{\circ} \mathrm{C} / \mathrm{wm}^{-2}$.

Swingedouw [20] uses a range in solar forcing at the earth's surface of approximately $0.6 \mathrm{wm}^{-2}$ for the last millennium to 1850 . Schmidt [21] is consistent with this range being less than $0.3 \mathrm{wm}^{-2}$ for this period, after an adjustment for albedo and geometry of $17 \%$. This solar forcing is the main contributor to the $0.8^{\circ} \mathrm{C}$ to $1.1^{\circ} \mathrm{C}$ range in temperature observed over this period. See Esper [22], Ljungqvist [23], Moberg [24] and Loehl [25] for the relevant temperature series. The simulated Paleoclimate Modelling Intercomparison Project Phase 3 (PMIP3)/CMIP5 multi-model mean gives a simulated range in temperature, after isolated spikes due to volcanic activity have been removed, of $0.3^{\circ} \mathrm{C}$ (AR5[26]) over this period which is not consistent with the temperature series given above or the approximately $0.8^{\circ} \mathrm{C}$ range featured in the AR5 [26] temperature reconstruction. This inconsistency manifests as a $0.5^{\circ} \mathrm{C}$ difference lasting for hundreds of years during the Middle Warming Period at around $1000 \mathrm{AD}$. This is dismissed without reference as internal variability in the AR5. The PMIP3/CMIP5 multi-model mean is, likely, not consistent with these temperature reconstructions because it's $\mathrm{E}_{(\mathrm{Solar})}$ is too low.

The climate sensitivity to a change in solar forcing, $1.4^{\circ} \mathrm{C} / \mathrm{wm}^{-2}$, used as an input to the model (Figure 1) can, therefore, be said to have a solid real world basis, and appears to be considerably more realistic than the PMIP3/CMIP5 multi-model mean over the last 1000 years.

The solar forcing history since 1880 was taken from Lean [27, 28]. From 2001 data from the Physikalisch Meteorologsches Observatorium Davos (PMOD/WRC) are used. See Frohlich [29, 30] for a description of the PMOD/WRC data. Twenty year lags are crudely allowed for by taking $25 \%$ of the current reading and adding $66 \%$ of the reading 10 years previous and $9 \%$ of the reading 20 years previous as outlined in Hansen [4]. The actual input to the model is listed in "Appendix 2".

\subsection{Aerosols}

The AR5 [31] gives an aerosol forcing in 2010 of $-0.9(-1.9$ to -0.1$) \mathrm{wm}^{-2}$. The uncertainty given is $(5 \%$ to $95 \%)$.

The total aerosol cooling used on a best fit basis in the model (Figure 1) for 2010 is $-0.2^{\circ} \mathrm{C}$ which is at the low end of the AR5[31] estimates but still within their range. A low estimate is consistent with the current temperature hiatus occurring at a time when atmospheric aerosols are falling (Mishchenko [32]) and there being more warming in the northern hemisphere than the south despite more industrial aerosol cooling occurring in the north.

The history of aerosol cooling from 1880 to 2010 was taken from Stern [33] and was based on sulphate estimates only with an uncertainty implied of $\pm 8 \%$. The actual inputs to the model (Figure 1) are listed in "Appendix 2". 


\subsection{Internal Variability}

Internal variability is not considered to be a forcing as it will always even out over time. Because the relationship between $\mathrm{E}_{(\mathrm{Solar})}$ and $\mathrm{E}_{(\mathrm{GHG})}$ is not known these parameters in the model (Figure 1) can be varied on a best fit basis to suit more accurate estimates of internal variability as our knowledge increases.

A crude history of internal variability was calculated by adding the PDO and AMO indexes from 1880 to 2010. A best fit for the model (Figure 1) in degrees Celsius was found by dividing this combined index by 7.7. The actual inputs to the model (Figure 1) are listed in "Appendix 2".

\subsection{Green House Gases}

The GHG forcing parameter used is about $0.35^{\circ} \mathrm{C} / \mathrm{wm}^{2}$ or $1.3^{\circ} \mathrm{C}$ for $\mathrm{CO} 2$ doubling. This was done on a best fit basis and assumed that equilibrium and transient temperature were approximately the same due to the oceans being virtually opaque to long wave GHG radiation. See "Appendix 1".

The GHG forcing history over the 1880 to 2010 period was calculated as described in "Appendix 3" and included all the anthropogenic GHGs not just $\mathrm{CO} 2$. The actual inputs used in the model (Figure 1) are listed in "Appendix 2".

\section{Conclusion}

The accuracy of the model (Figure 1) $\left(\mathrm{R}^{2}=0.89\right)$ since 1880 gives support to my proposition that $\mathrm{E}_{(\mathrm{GHG})}$ is likely to be considerably lower than $\mathrm{E}_{(\mathrm{Solar})}$. That there is a physical basis for this is also discussed in the introduction and confirmed by the simple experiment in "Appendix 1".

It is established physics that the oceans are opaque to the long wave radiation reemitted by GHGs while short wave solar radiation readily transports energy to a depth of many meters. Long wave GHG radiation is quickly returned to the atmosphere and, eventually, space as latent heat of evaporation as is demonstrated in "Appendix 1". If established, this fact can only lead to the conclusion that a Radiative flux imbalance at the TOA caused by increasing GHGs will likely be restored to balance more quickly than a similar sized flux imbalance caused by changes in solar radiation.

It follows that climate sensitivity to changes in GHG forcing is likely to be considerably lower than for similar changes in solar forcing. It is becoming increasingly obvious that no model, with a solid physical basis, can accurately track the slope of the temperature increase from 1910 to 1940, the cooling from 1940 to 1970 , the slope of the increase from 1970 to 1998 , and the current temperature hiatus without assuming $\mathrm{E}_{(\mathrm{GHG})}$ is considerably lower than $\mathrm{E}_{(\text {Solar })}$. 


\section{Appendix 1}

The experiment outlined in appendix 1 is based on and reproduces the work of Konrad Hartmann and Roger Tattersal. I have conducted the experiment myself and confirmed their results, but have used their results in this paper.

- I have no reference to the original paper and suggest that it is the result of the test that is critical to this paper. Any reader is free to conduct the test as described.

Where water is free to evaporate, test " $\mathrm{A}$ " shows that back radiation from GHGs will have a negligible effect on the heat content of that water. Test "B" shows that nearly all the energy from an increase in back radiation from GHGs is returned to the atmosphere as latent heat of evaporation. It follows that any Radiative flux change at the TOA will likely be restored more quickly if it is caused by a change in GHG forcing than if it is caused by a change in solar forcing.

\subsection{Konrad: Empirical test of ocean cooling and back radiation theory}

What follows is an edited version of the Konrad experiment design, results, comment and interpretation. I would encourage others to conduct similar experiments to check these results. The results appear to show the measurable difference between reflecting Long Wave Infrared Radiation (LWIR) back to warm water when it is free to evaporatively cool and when it can only cool through conduction and radiation.

\subsubsection{Equipment}

- Two identical probe type digital thermometers with 0.1 degree resolution

- Two identical insulated water containers. I used rectangular $200 \mathrm{ml}$ Tupperware style containers, insulated on their base and sides with foil and Styrofoam. I cut away the clip on rim from each lid to create a frame to clip down cling film for Test B of the experiment.

- One IR reflector. I used an A4 sheet of $10 \mathrm{~mm}$ Styrofoam with aluminum foil attached with spray adhesive.

- One IR window. I built an A4 size "picture frame" of $10 \mathrm{~mm}$ square balsa wood strips and stretched cling film over it.

- One 1 litre measuring jug

- Two small identical computer fans. I used Suron 50mm centrifugal blowers powered by a $6 \mathrm{v}$ gel cell battery

\subsubsection{Method}

- Position probe thermometers in identical positions in both water containers. I placed the tips $10 \mathrm{~mm}$ below the water line by drilling force fit holes in the sides of the containers.

- Position IR reflector and IR window 50mm above either water container. You may need to build two Styrofoam side walls, but air must be free to 
- Move over the surface of the water. (The use of the IR window is to ensure that air flow is similar over each water container.)

- Position the computer fans to blow across the water surface of each container, but do not turn on.

- Fill jug with warm water, stir, then fill each water container from the bucket. I used water around $40 \mathrm{C}$ as the ceiling was around $18 \mathrm{C}$ not a $3 \mathrm{k}$ sky.

- When an equal amount of water is in each container, turn on the computer fans.
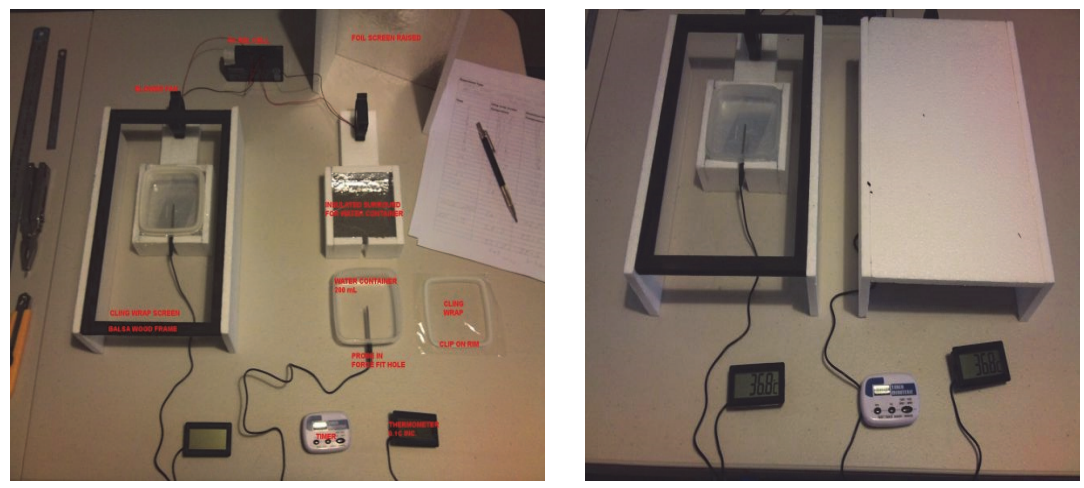

Figure A.1: Experimental Method

- Observe the temperature change over time for each tank. Less than half an hour both tanks cool at the same rate (TEST A).

- Now the important bit - Repeat the experiment, but this time lay a small sheet of cling wrap on the surface of the water in each water tank. This allows cooling through radiation and conduction but prevents evaporation. You do not need the computer fans on in this test. You should be able to observe that while both containers cool slower than before, water under the IR reflector cools slowest (TEST B).

\subsubsection{Interpretation}

In TEST A the water cools more quickly, however the two water containers temperatures remain very close to each other over time. This indicates that backscattered LWIR has a very limited effect on the rate of cooling for water when it is free to evaporatively cool.

In TEST B both water containers cool more slowly than Test A, but a divergence in temperature between the two water containers is readily detectable. The container under the foil sky cools more slowly than that under the cling wrap sky. This indicates that backscattered LWIR from a warm material can 
slow the rate at which that material cools, if radiation and conduction are the only methods for cooling.

Test A represents the evaporative cooling conditions in the real oceans. . From what I have observed, backscattered LWIR can slow the rate at which substances cool. However in the case of liquid water that is free to cool evaporatively this effect is dramatically reduced. It would appear that including the oceans in the percentage of Earth's surface that could be affected by backscattered LWIR may be a serious error. Earth's oceans cover $71 \%$ of the planet's surface. If backscattered LWIR cannot measurably affect liquid water temperature, then $\mathrm{E}_{(\mathrm{GHG})}$ is likely to be considerably lower than $\mathrm{E}_{(\mathrm{Solar})}$.

\subsubsection{Results}

Table 1: $\quad$ Typical Test A

\begin{tabular}{|l|l|l|}
\hline Time & Cling Wrap Screen & Foil Screen \\
\hline 0 & 37.1 & 37.1 \\
\hline 5 & 33.2 & 33.2 \\
\hline 10 & 29.4 & 29.4 \\
\hline 15 & 27.0 & 26.9 \\
\hline 20 & 25.5 & 25.5 \\
\hline 25 & 24.5 & 24.5 \\
\hline
\end{tabular}

Table 2: $\quad$ Typical Test B

\begin{tabular}{|l|l|l|}
\hline Time & Cling Wrap Screen & Foil Screen \\
\hline 0 & 38.2 & 38.2 \\
\hline 5 & 36.3 & 36.6 \\
\hline 10 & 34.8 & 35.3 \\
\hline 15 & 33.5 & 34.2 \\
\hline 20 & 32.6 & 33.4 \\
\hline 25 & 31.5 & 32.6 \\
\hline
\end{tabular}

\section{Appendix 2}

Below are the four inputs to the model (Figure 1). All inputs are translated into their effect on the earth's transient temperature in degrees Celsius. 


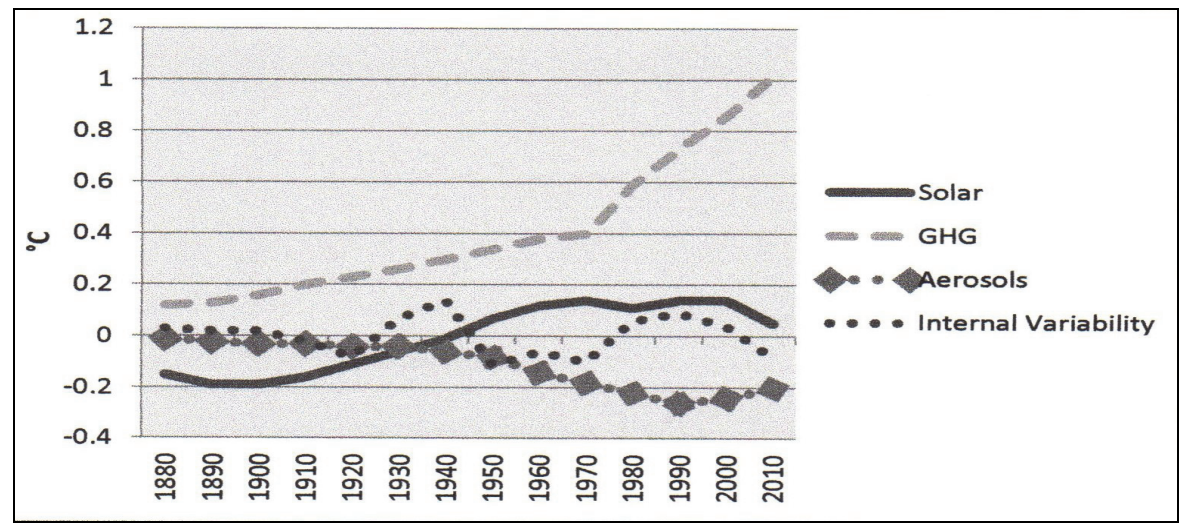

Figure 3: $\quad$ Model Input Data

Table 3: Model Input Data Table

\begin{tabular}{|l|l|l|l|l|l|l|l|l|}
\hline Year & $\begin{array}{l}\text { Solar } \\
\mathrm{x} 1.4{ }^{\circ} \mathrm{C}\end{array}$ & $\begin{array}{l}\text { GHG } \\
\mathrm{x} .35^{\circ} \mathrm{C}\end{array}$ & $\begin{array}{l}\text { AMO } \\
\text { Index }\end{array}$ & $\begin{array}{l}\text { PDO } \\
\text { Index }\end{array}$ & $\begin{array}{l}\text { AMO+PDO } \\
/ 7.7{ }^{\circ} \mathrm{C}\end{array}$ & $\begin{array}{l}\text { Aerosols } \\
{ }^{\circ} \mathrm{C}\end{array}$ & $\begin{array}{l}\text { Total } \\
{ }^{\circ} \mathrm{C}\end{array}$ & $\begin{array}{l}\text { NOAA } \\
{ }^{\circ} \mathrm{C}\end{array}$ \\
\hline 1880 & -0.15 & 0.12 & 0.05 & 0.2 & 0.03 & -0.01 & -0.01 & 0.08 \\
\hline 1890 & -0.19 & 0.13 & -0.03 & 0.2 & 0.02 & -0.02 & -0.06 & 0 \\
\hline 1900 & -0.19 & 0.16 & -0.08 & 0.2 & 0.02 & -0.03 & -0.04 & 0.04 \\
\hline 1910 & -0.16 & 0.2 & -0.25 & 0.1 & -0.02 & -0.03 & -0.01 & -0.08 \\
\hline 1920 & -0.11 & 0.23 & -0.19 & -0.4 & -0.08 & -0.04 & 0 & 0 \\
\hline 1930 & -0.06 & 0.26 & 0.15 & 0.4 & 0.07 & -0.04 & 0.23 & 0.1 \\
\hline 1940 & -0.01 & 0.3 & 0.3 & 0.8 & 0.14 & -0.06 & 0.37 & 0.32 \\
\hline 1950 & 0.07 & 0.34 & 0.08 & -0.9 & -0.11 & -0.08 & 0.23 & 0.15 \\
\hline 1960 & 0.12 & 0.38 & 0.04 & -0.5 & -0.06 & -0.14 & 0.3 & 0.27 \\
\hline 1970 & 0.14 & 0.4 & -0.17 & -0.6 & -0.1 & -0.08 & 0.26 & 0.25 \\
\hline 1980 & 0.11 & 0.59 & -0.12 & 0.6 & 0.06 & -0.22 & 0.54 & 0.38 \\
\hline 1990 & 0.14 & 0.73 & -0.09 & 0.8 & 0.09 & -0.26 & 0.7 & 0.5 \\
\hline 2000 & 0.14 & 0.86 & 0.3 & -0.01 & 0.04 & -0.24 & 0.8 & 0.8 \\
\hline 2010 & 0.05 & 1.02 & 0 & -0.6 & -0.08 & -0.2 & 0.79 & 0.8 \\
\hline
\end{tabular}

\section{Appendix 3}

The history of GHG forcing since 1880 was calculated as follows.

- A preindustrial CO2 concentration of $280 \mathrm{ppm}$ was assumed. CO2 concentrations since 1880 were taken from the IPCC pre 1960 and from Mauna Loa after 1960.

- $\mathrm{CO} 2$ Forcing was calculated using the widely accepted formula ;

$$
\triangle \mathrm{F}=5.35 \mathrm{x} \ln \left(\mathrm{C} / \mathrm{C}_{0}\right) \mathrm{wm}^{-2} \text {. }
$$

Where " $\mathrm{C}$ " is the current $\mathrm{CO} 2$ concentration and " $\mathrm{C}_{0}$ " is the initial $\mathrm{CO}_{2}$ concentration. Based on the IPCC's Third Assessment Report (TAR) and 4AR 
forcings bar graphs, the $\mathrm{CO}_{2}$ forcing was then multiplied by 1.66 to give the total forcing of all the AGHGs $\left(\mathrm{NO}_{2}, \mathrm{CH}_{4}\right.$, Halogens etc.)

\section{References}

[1] WG1 contribution to the IPCC's AR5-The Physical Science Basis. Technical Assessment. 23-26 September, 2013. 12 ${ }^{\text {th }}$ Session. Efficacy Discussion.

[2] IPCC's 4AR, WG1, Chapter 2.8.5. 2007. Efficacy Discussion.

[3] Forster, P.M.F., \& Taylor, K.E., - Climate Forcings and Climate sensitivities Diagnosed from Climate Model Integrations Coupled. Journal of Climate, 6183, 2006.

[4] Hansen, J., Sato, M., Kharecha, P., von Schuckmann, K., - Earth's Energy Imbalance \& Implications. Atmos. Chem. Phys. Discuss, 11, 27031-27105, pp 19-21, 2011.

[5] Forster, P.M. de F., \& Gregory, J.M., - The Climate Sensitivity and it's Components Diagnosed from Earth Radiation Data. Journal of Climate. 19, issue 1, 39-52, 2006

[6] von Storch, H., - Can climate models explain stagnation in global warming? Unpublished, Academia.edu, pp 1, 2013.

[7] Mauritsen, T., Stevens, B., Roeckner, E., Crueger, T., Esch, M., Giorgetta, M., Haak, H., Jungclaus, J., Klocke, D., Matei, D., Mikolajewicz, U., Notz, D., Pincus, R., Schmidt, H., \& Tomassini, L. - Tuning the climate of a global model. Journal of advances in modelling earth systems. Vol 4, M00A01. Doi: 10.1029/2012M, 5000154, 2012.

[8] Cohen-Tanugi, D \& Held, I., - Model and parameter dependence in estimating oceanic effects on climate response to radiative forcing. Geophysical fluid dynamics laboratory, Princeton University. 2008

[9] Mann, M.E., Steinman, B.A., Miller, S.K.,- On forced temperature changes, internal variability and the AMO. Geophysical Research Letters. Revised March 12, 2014.

[10]Lewis, N. - http://climateaudit.org/2014/05/19/manns-new-paperrecharacterizing-the-atlantic-multidecadal-oscillation/

[11] WG1 AR5, Technical Summary, TS 4.2 TS 27

[12] Peterson, T. C., and M. O. Baringer, Eds.,: State of the Climate in 2008. Bull. Amer. Meteor. Soc., 90, S1-S196, 2009 Noaa climate report 2008

[13] Cazenave, A., \& Llovel, W., - Contemporary sea level rise. Annu. Rev. Mar. Sci. 2:145-73. Doi: 10.1146/annurev-marine-120308-081105, 2010

[14] Gordon, H.R., \& Morel, A., - Remote assessment of ocean color for interpretation of satellite visible imagery, - A review. Spring-Verlag. $114 \mathrm{pp}, 1983$.

[15] Morel, A., - Optical modelling of the upper ocean in relation to it's biogenous matter content (case 1 waters). - J. Geophys. Res., 93. 1074910768. 1988. 
[16] Ohlmann, J.C., Siegel, D.A. \& Gautier, C., - Ocean mixed layer radiant heating and solar penetration. A global analysis. J. Climate. 9, 2265-2280. 1996.

[17] Siegel, D.A., Ohlmann, J.C., Washburn, L., Bidigare, R.R., Nosse, C., Field, E. \& Zhou, Y. - Solar radiation, phytoplankton pigments, and radiant heating of the equatorial pacific warm pool. - J. Geophys. Res., 100, 4885-4891. 1995.

[18] Shaviv, N.J., - On Climate Response to Changes in the Cosmic Ray Flux and Radiative Budget. Journal of Geophysical Letters, vol. 110, A08105, doi; 10. 1029/2004JA10866, 2005.

[19] Annan, J.D., \& Hargreaves, J.C., - Using Multiple Observational - Based Constraints to Estimate Climate Sensitivity. Geophysical Research Letters, 33, issue 6, L06704, doi; 10. 1029/2005 GL025259, 2006.

[20] Swingedouw, D., Terray, L., Cassau, C., Voldoire, A., Salas-Melea, D., Servonnat, J.,- Natural forcing of climate during the last millennium: Fingerprint of solar variability. Clim Dyn, vol 36, 1349-1364, doi, 10. 1007/s00382-010-0803-5, 2011.

[21] Schmidt, G.A., Jungclaus, J.H., Ammann, C.M., Bard, E., Braconnot, P., Crowley, T.J., Delaygue, G., Joos, F., Krivova, N.A., Muscheler, R., OttoBliesner, B.L., Pongratz, J., Shindell, D.T., Solanki, S.K., Steinhilber, F., \& Vieira, L.E.A. - Climate forcing reconstructions for use in PMIP simulations of the last millennium (v 1.0). Geosci. Model Dev. 4, 33-45, 2011.

[22] Esper, J., Cook, E.R., \& Schweingruber, F.H., - Low Frequency Signals in Long Tree Ring Chronologies for Reconstructing Past Temperature Variability. Science, vol. 295, 2250-2252, 2002.

[23] Ljungqvist, F.C., - A New Reconstruction of Temperature Variability in the Extra-Tropical Northern Hemisphere During the Last Two Millenia. Geografiska Annaler, 92 A(3), 339-351, 2010.

[24] Moberg, A., Sonechkin, D.M., Holmgren, K., Datsenko, N.M. \& Karlen, K., - High Variability Northern Hemisphere Temperatures Reconstructed from Low- and High-Resolution Proxy Data. Nature, 433, 613-617, doi; 10. 1083/nature03265. 2005.

[25] Loehl, C., - A 2000 Year Temperature Reconstruction Based on Non-Tree Ring Proxies. Energy and Environment, vol. 18, 1049-1058, 2008.

[26] IPCC's AR5, WG1, Box TS. 5. Figure 1, Technical Summary - Final Draft. 7 th June 2013.

[27] Lean, J., Beer, J. \& Bradley, R. - Reconstruction of Solar Irradiance Since 1610. Implications for Climate Change. Geophysical Research Letters, vol. 22, issue 23, 3195-3198, 1995.

[28] Lean, J. - Evolution of the Sun's Spectral Irradiance Since the Maunder Minimum. Geophysical Research Letters, vol. 27, issue 16, 2425-2428, 2000.

[29] Frohlich, C. - Observations of Irradiance Variations. Space Science Reviews, 00: 1-10, 2000. 
[30] Frohlich, C. - Long Term Behaviour of Space Radiometers. Metrologia, 40, s60, doi: 10. 1088/0026-1394/40/1/314, 2003.

[31] IPCC's AR5, WG1, Chapter 7, Executive Summary. Technical Summary Final Draft. $7^{\text {th }}$ June 2013.

[32] Mishchenko, M.I., Geogdzhayev, I.V., Rossow, W.B., Cairns, B., Carlson, B.E., Lacis, A.A., Liu, L. \& Travis, L.D. - Long term satellite record reveals likely recent aerosol trend. Science, 345, 1543, doi: 10. 1126/Science. 1136709, 2007.

[33] Stern, D.I., - Reversal in the trend in global anthropogenic sulphur emissions. 16, 207-220, doi: 10. 1016/j.gloenvcha.2006.01.001, 2006. 